This is the author's version of:

Blanca Ramírez Barat, Emilio Cano, Paola Letardi, "Advances in the design of a gel-cell electrochemical sensor for corrosion measurements on metallic cultural heritage" Sensors and Actuators B: Chemical, Volume 261, 2018, Pages 572-580,

https://doi.org/10.1016/j.snb.2018.01.180. 


\title{
Advances in the design of a gel-cell electrochemical sensor for corrosion measurements on metallic cultural heritage
}

\author{
Blanca Ramírez Barat, Emilio Cano, Paola Letardi \\ ${ }^{1}$ Centro Nacional de Investigaciones Metalúrgicas (CENIM), Consejo Superior de \\ Investigaciones Científicas (CSIC), Av. Gregorio del Amo 8, 28040 Madrid (Spain) \\ ${ }^{2}$ Institute of Marine Sciences (ISMAR), Consiglio Nazionale delle Ricerche, (CNR), Via de Marini \\ 6, Genoa, Italy \\ * Corresponding author: Blanca Ramírez Barat, blanca.ramirez@csic.es
}

\section{Highlights:}

- An electrochemical sensor for corrosion studies on cultural heritage has been designed.

- The effects of the cell setup on EIS measurements are evaluated.

- Cell contribution can be discriminated from the working electrode response.

- Field measurements on outdoor sculpture are comparable to laboratory results.

- The cell has proved to be a useful tool for in situ conservation assessment.

\begin{abstract}
Electrochemical impedance spectroscopy (EIS) is widely used in corrosion studies and coatings evaluation for metals. However, its applicability to conservation problems in the field cultural heritage is limited by the practical difficulties of performing in-situ measurements on sculptures and monuments. Authors have proposed use of a gel polymer electrolyte (GP-E) cell as an electrochemical sensor to overcome the difficulties of handling liquid electrolytes on irregular surfaces. The aim of this paper is to optimize the design of the G-PE cell for in-situ EIS measurements on metallic cultural heritage, and to characterize in detail the possible effects of the configuration of the cell on the EIS spectra. Parasitic impedances from the reference electrodes have been analyzed to discriminate the response of the working electrode from that arising from artifacts from the cell setup, in order to be able to make an accurate interpretation of the results. This has allowed optimizing the different parameters and designing an effective tool for conservation assessment in metallic cultural heritage.
\end{abstract}

\section{Keywords}

electrochemical sensor, electrochemical impedance spectroscopy, gel electrolytes, cultural heritage, corrosion 


\section{Introduction}

The use of electrochemical impedance spectroscopy (EIS) for the evaluation of patinas and coatings in the field of cultural heritage has raised some interest in the latest decades. Traditional coatings usually applied by conservators such as acrylic resins and waxes have been evaluated using this technique, which has also been used for testing in the development of new coatings and inhibitors [1-8]. Besides these studies, researchers have also worked in the development of portable systems to carry out EIS measurements directly on sculptures and monuments [9-12]. As in other applications, to measure in-situ corrosion, specific sensors need to be developed which are specially adapted to the characteristics of the system under study [13-15]. These field studies are of great importance for cultural heritage conservation, as they provide a proof of coatings performance in real conditions and allow evaluating the conservation condition of the object under study and, in consequence, helping to assess conservation treatments and decisions [16].

The difficulties in applying this technique in the field of metallic cultural heritage can be summarized in two aspects. From a practical point of view, mounting an electrochemical cell on the irregular and non-flat surface of a monument is not an easy task. The second challenge is in interpreting results obtained from complex surfaces with low conductivity electrolytes. Practical difficulties and the different approaches that have been proposed to tackle them have already been discussed in previous papers [17-19]. Among the possible solutions to use EIS for in situ measurements, authors have proposed an agar gelled electrolyte (G-PE) cell which has given promising results $[18,20]$. The gelled electrolyte has shown to provide good quality and reproducible results without damaging the surface of the sculpture or monument [18]. Another advantage of the G-PE cell over other alternatives is the fact that it is not limited to a pseudoreference electrode, and a real reference electrode can be incorporated in the cell. For convenience, the initial setup of the G-PE cell used a pseudo-reference electrode, but the use of a real reference electrode would allow measuring the real electrochemical potential of working electrode.

A rough comparative approach based on the low frequency impedance modulus may sometimes be used. Nonetheless a full exploitation of the information content in the EIS spectra, besides the complexity of the surface, requires taking into consideration the possible contribution of the measuring setup also. Authors have already drawn attention on the fact that the use of low conductivity electrolytes needed to avoid alteration of the metallic cultural heritage surface can make the cell impedance not negligible [21]. It has already been demonstrated that, on a 3electrode measurement configuration, artifacts can appear on EIS measurements due to the coupling of the working, reference and counter electrodes [22,23]. Depending on the geometry of the cell and the conductivity of the electrolyte, these artifacts can distort the EIS in the frequencies of interest for corrosion studies (typically $100 \mathrm{kHz}$ to $1 \mathrm{mHz}$ ) [24-26], and therefore an accurate interpretation of the working electrode impedance requires special attention to this issues. Another source of distortion of the EIS spectra is the impedance of the reference electrode, which is usually neglected. However, it has been demonstrated that a highimpedance reference electrode can be responsible for parasitic elements in the fitting equivalent circuit [27]. 
The aim of this paper is to optimize the design of the G-PE cell for in-situ EIS measurements on metallic cultural heritage, and to characterize in detail the effects on the results of the configuration of the cell, including composition of the electrolyte, type of reference and counter electrodes used, and geometric arrangement of the different elements. A deep understanding of these effects is necessary to be able to make an accurate interpretation of the result obtained on real heritage objects using this cell.

\section{Experimental.}

\subsection{Cell construction}

From the initial prototype [20]several changes have been introduced in the cell design to improve its performance and handling. The cell design is based on a traditional three electrode cell, in which the electrolyte is introduced into a cylinder container with the reference (RE) and counter-electrode (CE) and then placed over the object under study, i.e., the working electrode (WE). The container is made of two hard plastic pieces which act as a mold for the gel. One cylindrical piece supports the electrolyte and electrodes; a second piece acts as a cap and it is removed after the electrolyte solidifies, leaving the first millimeters of the gel cylinder exposed to allow good contact with the WE (figure 1).

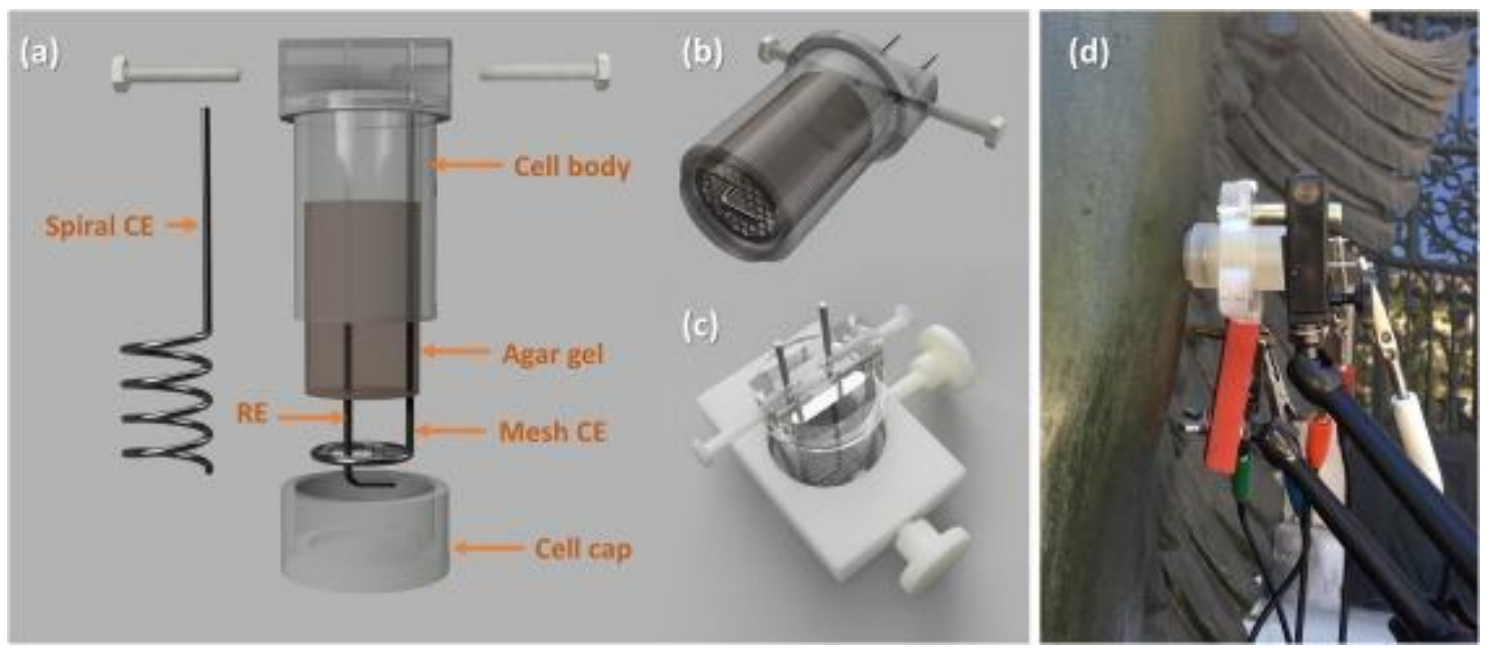

Fig. 1. Cell design: exploded view (a) mounted cell (b) and support (c). The picture in the right (d) shows the complete measuring setup on the surface of an outdoor sculpture.

In the first prototype the cell was constructed with a $2.7 \mathrm{~cm}$ diameter grey PVC tube. In this second design the overall shape of the cell has been modified. The base cylinder is now longer and thinner, $2 \mathrm{~cm}$ diameter, and has been made with transparent methacrylate. This shape facilitates positioning of the cell in field studies. However, the exact size of the cell can be modified according to the needs of the precise surface to be measured: larger areas might improve the signal, resulting in cleaner spectra; and smaller areas can be used to measure in narrow spaces or complex geometries. The transparency of the material allows seeing if any bubbles have been trapped in the gel and also the contact between the electrolyte and the metal surface. Electrodes are fixed with a couple of nylon screws to a fixed distance (figure $1 \mathrm{a}-\mathrm{b}$ ). 
The cell is fixed on a square plastic support (figure 1c) which is attached to a double articulated arm, that can be locked in any position with a single central locking knob. This arm is fixed on a tripod with an extensible arm, which allows positioning the cell in the desired place (figure 1d). A light pressure is applied, making the flexible gel to adapt to the irregular surface and causing an expulsion of a small amount of electrolyte from the gel (syneresis) which ensures a proper wetting of the surface and assures the ionic conductivity.

The same base cylinder may be used as a standard cell setup if filled with liquid electrolyte; this design allow for a more straightforward comparison between the setup usually adopted for laboratory measurements and the G-PE cell setup to be used on field measurements.

\subsection{Electrodes}

Pseudo reference electrodes made of stainless steel wire (AISI 316L) and 99.9\% silver electrochemically coated with $\mathrm{AgCl}$ have been compared to an $\mathrm{Ag} / \mathrm{AgCl}(\mathrm{KCl} 1 \mathrm{M})$ reference electrode by $\mathrm{CH}$ Instruments. The electrochemically $\mathrm{AgCl}$ coated silver wire was prepared as follows: the silver wire was polished with 2000 grain emery paper and then introduced in a $0,05 \mathrm{M} \mathrm{KCl}$ solution and an anodic $3.0 \mathrm{~V}$ potential vs $\mathrm{Ag} / \mathrm{AgCl}$ reference electrode was applied for 10-20 minutes until the surface was coated with a grayish-white layer of silver chloride [28]. A stainless steel mesh or a stainless steel spirals (AISI 316L) have been used as a counter electrode.

Shape and position of electrodes has been designed to minimize ohmic drops and current distribution inhomogeneity, taking into account that measurements will be done always in low conductivity electrolytes. Pseudo reference electrodes are $L$ shaped, with the lower part close to the WE, to minimize the ohmic drop, and parallel to the surface the WE. The non-measuring part of the electrode is covered with a heat shrink sleeve. The CE was also placed parallel to the WE surface and above the RE, covering an area as equal as possible to the WE. This configuration was chosen to ensure a uniform and parallel distribution of the current lines, and having the sensing part of the RE in an equipotential line [25, 29].

Results obtained with different electrodes are shown in the figures with the following labels: $<$ StdRE $>,<$ SRE $>$ and $<$ AgRE $>$ for "standard", "stainless steel" and "AgCl coated Ag wire reference electrodes respectively, while the suffix $<-$ e $>$ or $<-$ m $>$ stands for spiral or mesh CE.

\subsection{Electrolyte}

The electrolyte has been prepared by gelling a liquid electrolyte with agar (technical grade). As liquid electrolyte, artificial rain $\left(\mathrm{CaSO}_{4} \cdot 2 \mathrm{H}_{2} \mathrm{O} 14.43 \mathrm{mg} / \mathrm{L},\left(\mathrm{NH}_{4}\right)_{2} \mathrm{SO}_{4} 15.04 \mathrm{mg} / \mathrm{L},\left(\mathrm{NH}_{4}\right) \mathrm{Cl}\right.$ $19.15 \mathrm{mg} / \mathrm{L}, \mathrm{NaNO}_{3} 15.13 \mathrm{mg} / \mathrm{L}$ and $\mathrm{CH}_{3} \mathrm{COONa} \mathrm{mg} / \mathrm{L}$ ) has been used, adapted from [30]. The solution is prepared 1000 fold concentrated and $\mathrm{pH}$ adjusted to 5 with $\mathrm{HNO}_{3}$ and stored at room temperature. This solution has then been diluted to a 10 -fold concentration, with a final $\mathrm{pH}$ value of 6.5. This solution has been chosen because it has a similar composition to the natural electrolyte to which outdoor monuments are exposed and at the same time it is a mild electrolyte which prevents any damage to the surface. To prepare the electrolyte $3 \% \mathrm{w}-\mathrm{v}$ agar powder is added to the electrolyte in a beaker and gently heated in a microwave at low power until dissolution. The electrolyte is left to cool for a short time before pouring it on the mold, and then left to cool until solidification. After each use the gel electrolyte is removed from the 
cell and renewed. The measured conductivity was $72 \mu \mathrm{S} / \mathrm{cm}$ for the liquid electrolyte (LIQ) and $716 \mu \mathrm{S} / \mathrm{cm}$ for the agar gelled electrolyte (AA).

\subsection{Coupons}

Electrochemical measurements have been carried out on different metal coupons. Laminated AISI 316 stainless steel (SS), has been used as received as bare reference testing material for different cell configurations. Stainless steel provides a passive, very reproducible, uniform and smooth surface, to reduce possible variations in the measurements attributable to changes in the working electrode and allowing a better discrimination of cell contribution from WE behavior. In addition, some measurements have been done in bronze coupons. As bronze is one of the most representative materials in metallic cultural heritage, this has been done to compare and validate with results obtained in the stainless steel reference system. Two different bronze coupons have been used. Laminated EN 1652 CuSn5 bronze (95 Cu, $5 \mathrm{Sn} \% \mathrm{w}$ ) was selected as a simple bronze model (BL). Bronze coupons were grit with 1200 emery paper to obtain a clean homogeneous surface, and left to the air for several weeks to allow a thin oxide layer to grow reducing the high reactivity of a freshly polished surface. EN 1982 CC491K (DIN 1705-RG5) cast bronze ( $85 \mathrm{Cu}, 5 \mathrm{Sn}, 5 \mathrm{~Pb}, 5 \mathrm{Zn} \% \mathrm{w}$ ) was selected as a simile to real cast bronze sculptures (BF). Casted bronze was prepared by Codina Escultura, a traditional Spanish artistic foundry according to traditional materials and techniques. These coupons were used as received, i.e. with a rough surface (sandblasted) covered by a native oxide layer.

Finally, to test the cell's performance for in situ measurements on real cultural heritage assets in comparison to laboratory tests, measurements have been done on two sculptures: The sculpture "Mediterranea III", by the Spanish sculptor Martin Chirino, made out of stainless steel in 1971, and exposed in the Museo de Escultura de Leganés; and the right sphinx of the façade of the National Archaeological Museum in Madrid, made in 1894, by Felipe Moratilla y Parreto.

\subsection{Electrochemical measurements}

EIS spectra have been acquired using a Gamry 600 Potentiostat, using a frequency swept from $100 \mathrm{kHz}$ to $10 \mathrm{mHz}, 10 \mathrm{mV}$ RMS amplitude (at the open circuit potential, OCP) and 10 points/ decade. The system was left to stabilize at OCP for 30 minutes before measurements.

The area exposed to the electrolyte was $3.14 \mathrm{~cm}^{2}$ for the G-PE cell and $2.84 \mathrm{~cm}^{2}$ for the liquid cell. Analysis of the normalized spectra has been carried out using ZView software.

\section{Results and discussion}

Different series of measurements with different setups were performed to identify which design factors had a significant influence in the results and which ones where of minor relevance.

\subsection{The nature of the pseudo-reference electrode}

The $\mathrm{AgCl}$ coated silver wire from the first prototype [20] was compared to a stainless steel wire pseudo-reference electrode. The use of a pseudo-reference stainless steel electrode has been tested instead of the $\mathrm{AgCl}$ coated silver since it is cheaper, convenient and simplifies the experimental procedure, as does not require preparing the $\mathrm{AgCl}$ coat. Besides, this coat has to 
be eventually renewed as sometimes it becomes worn or detaches from the electrode. Results of impedance spectra of the gel cell with both electrode arrangements can be seen in figure 2 , both in stainless steel ( $2 a$ ) and bronze coupons ( $2 b$ and $2 c$ ). No meaningful differences can be enlightened between the $\mathrm{AgCl}$ coated silver and the stainless steel pseudo-RE, which supports the use of the latter.



Fig. 2. EIS spectra with stainless steel and $\mathrm{AgCl}$ coated $\mathrm{Ag}$ pseudo-reference electrodes on stainless steel (a), laminated bronze (b) and cast bronze (c).

A pseudo-RE does not have, in principle, an identifiable reversible electrochemical reaction nor a thermodynamically predictable behavior, therefore, these results are only valid in the reported conditions. For a stainless steel pseudo-RE, its potential and stability depends on the composition of the base alloy (mainly $\mathrm{Fe}, \mathrm{Cr}, \mathrm{Ni}$ and $\mathrm{Mo}$ ), the nature of the passive layer (mostly a mixture of $\mathrm{Cr}$ and $\mathrm{Fe}$ oxides and hydroxides) and the species in the medium. Wilburn et al., have proposed a metal-metal oxide type $\mathrm{pH}$-sensor behavior for stainless steel in a copolymer matrix of a fixed and constant $\mathrm{pH}$ value, in which the mixed oxide layer reacts reversibly with $\mathrm{H}^{+}$ ions $\left(\mathrm{M} / \mathrm{M}_{x} \mathrm{O}_{y}(\mathrm{~s})+{ }_{2} \mathrm{H}^{+}+2_{y} \mathrm{e}-\leftrightarrow \mathrm{M}(\mathrm{s})+{ }_{y} \mathrm{H}_{2} \mathrm{O}\right)$; thus in a constant $\mathrm{pH}$ media, it will provide a constant potential value that can be calculated according to Nerst equation [31]. In our cell, reactions with other species in the electrolyte (including dissolved oxygen) might play a significant role, so the $\mathrm{pH}$ dependence might not be accurate. Whether it may be of interest in applications where the absolute value of potential is relevant, further investigation of this issue is out of the scope of this paper. The alternative in our cell, will be the use of a real RE, which is discussed in section 3.3.

\subsection{The shape of the counter-electrode}

The simplification of the counter electrode has also been considered, substituting the stainless steel mesh by a stainless steel spiral, as it is easier to construct and facilitates the renewal of the gelled electrolyte after use. These two possible setups have been checked on different working electrodes (see figure 3), showing that, there are minimal differences between the mesh CE and the spiral CE, thus the differences are rather attributable to differences in the metal. Therefore, although the use of a mesh CE would be more appropriate from a theoretical point of view to 
ensure a uniform and parallel distribution of the current lines, from the practical point of view, a spiral CE can be used if preferred. This can be an option when large and/or periodic series of measurements for field-monitoring campaigns.

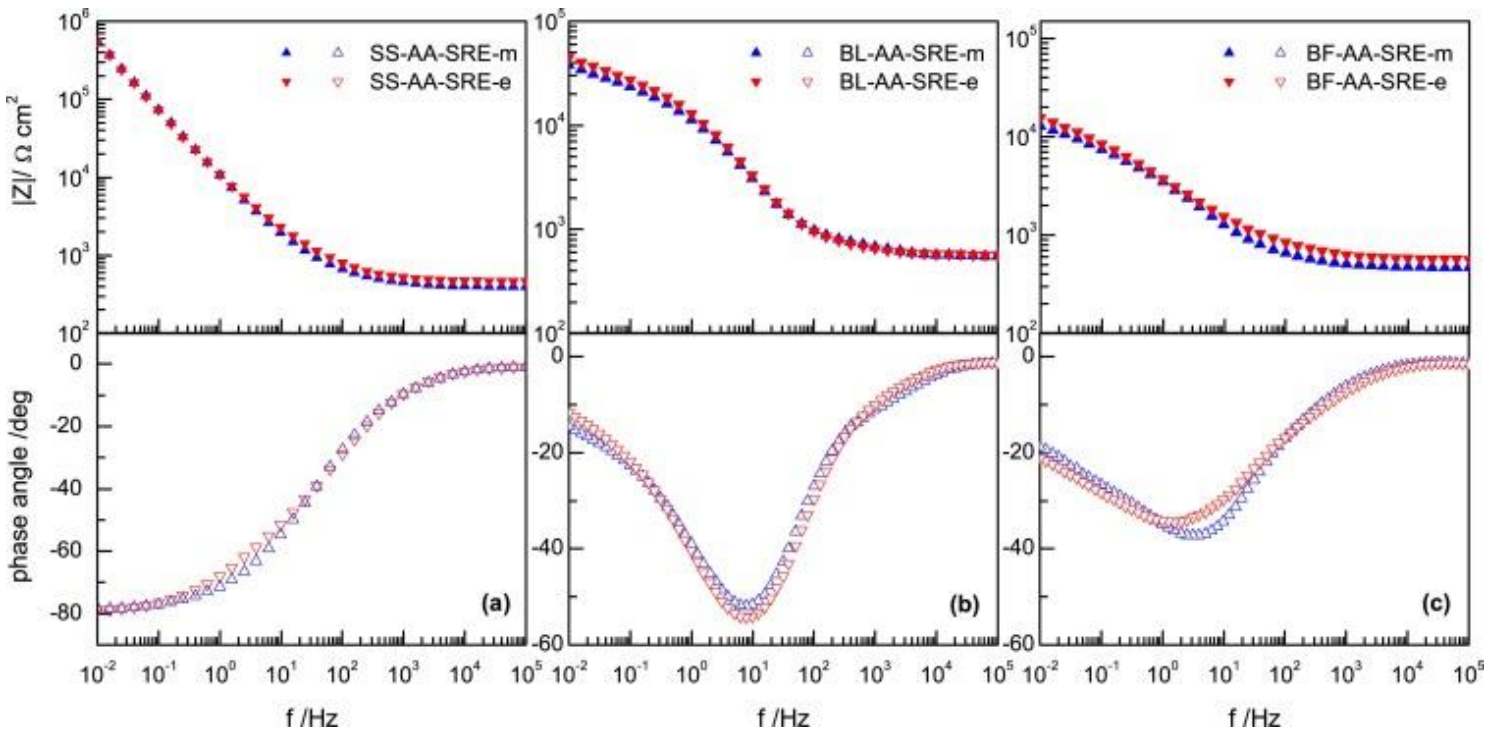

Fig. 3. EIS spectra using mesh and spiral counter electrodes on stainless steel (a), laminated bronze (b) and cast bronze (c).

\subsection{Real reference electrode vs pseudo-reference electrode}

To explore the possibility of using a real RE in the G-PE cell, measurements were done with an $\mathrm{Ag} / \mathrm{AgCl}$ reference electrode and compared with a steel pseudo-reference electrode. These measurements were performed both in liquid and agar gelled electrolyte, to compare also the behavior of the G-PE cell with a traditional setup. Results of impedance spectra on stainless steel coupons can be seen in figure 4 .

When substituting the pseudo-RE for the standard $\mathrm{Ag} / \mathrm{AgCl} \mathrm{RE}$ some relevant changes are observed. With the Std-RE uncompensated resistance, corresponding to the impedance at high frequencies appears to be lower. In the case of standard RE with the liquid electrolyte it can also be observed a distortion of the phase angle spectra at the high frequencies, between $10^{4}-10^{5} \mathrm{~Hz}$ (figure 4b), which denotes the presence of an artifact.

The spectra distortion at high frequencies caused by the RE and other elements of the measurement setup is a long time known problem, which started to be discussed in the 80's [31, 32]. In particular, the contribution of the RE can be significant in low conductivity media causing parasitic impedances $[32,33]$, in which interactions between the three electrodes are involved $[22,23]$. These parasitic impedances, commonly referred as stray capacitances frequently produce pseudo-inductive behaviors. While pseudo-inductive artifacts are easy to recognize as they appear as a loop in the fourth quadrant in Nyquist plot, capacitive artifacts might be more difficult to distinguish from real data [22]. 

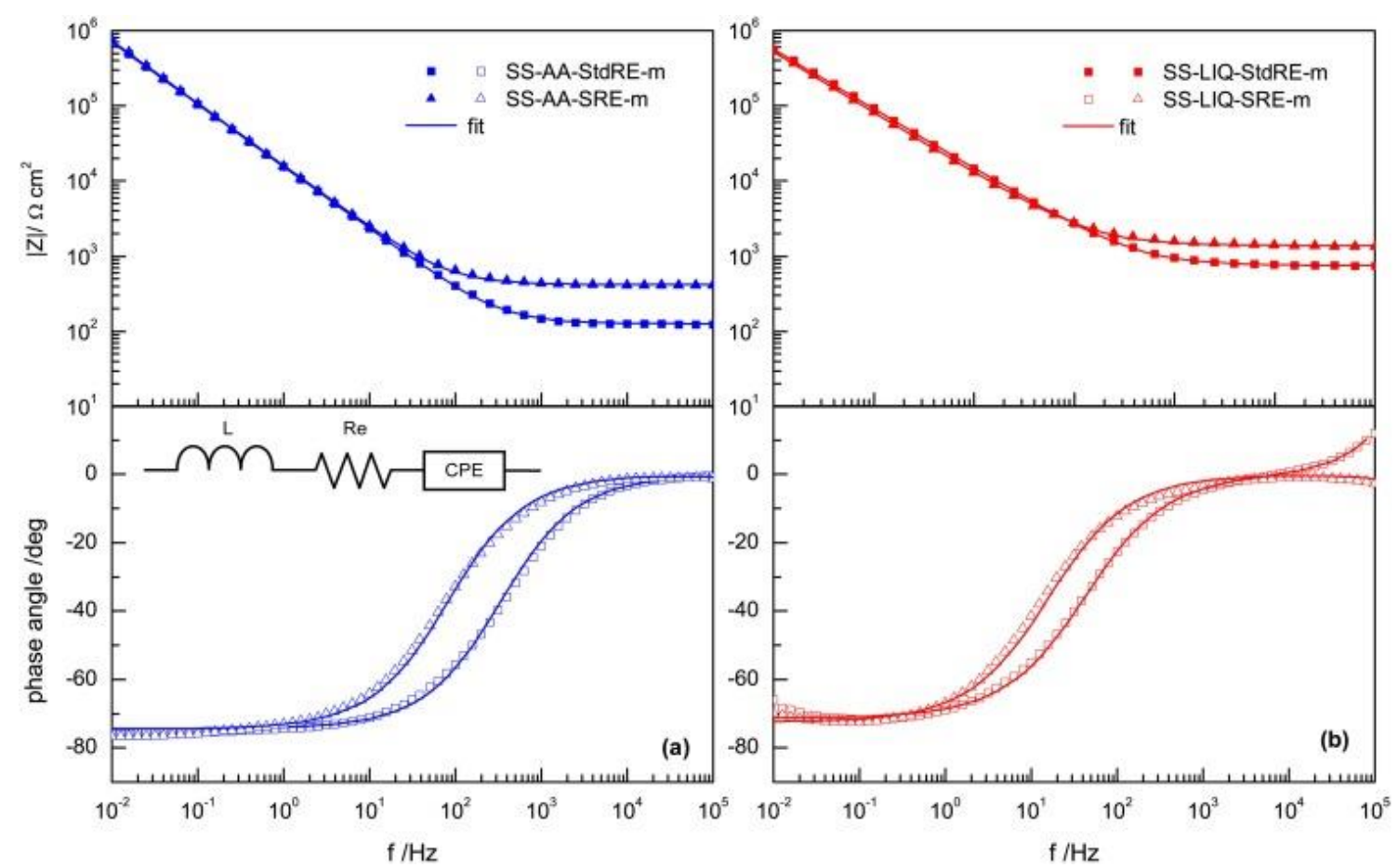

Fig. 4. EIS spectra comparing a real reference and a pseudo reference electrode on stainless steel coupons with gelled (a) and liquid electrolyte (b).

The key question now is to which extent this kind of artifact is present in our system and if it is possible to discriminate it from the WE response. Although this effect is not visible in the G-PE cell, we cannot automatically discard it, as it may be linked to the lower value of uncompensated resistance $\operatorname{Re}$ (the resistance of the electrolyte plus other contributions from the rest of the setup). The theoretical Re value can be easily calculated from the electrolyte layer conductivity and geometry using equation [1], where $\rho$ is the resistivity in $\Omega \cdot \mathrm{cm}$ (the inverse of the conductivity), $d$ is the distance between the RE and WE in $\mathrm{cm}$ and $A$ the contact area in $\mathrm{cm}^{2}$.

$$
R_{e}=\rho \frac{d}{A}
$$

For a $3.2 \mathrm{~mm}$ distance between the RE and WE used in these experiments, Re should be around $1556 \Omega$ for the liquid cell and $142 \Omega$ for the G-PE one. Thus, we can compare these calculated values with the experimental ones obtained by fitting the EIS spectra.

EIS spectra of agar and liquid cells with both real and pseudo RE have been fitted to the equivalent circuit in figure 4 , where $R e$ is the uncompensated resistance, the passive layer of stainless steel is represented by a constant phase element (CPE), and an inductor, L, has been used to model the artifacts from the measuring system. As it has been demonstrated by other authors, this inductive element arises from the reduction to a 2-pole electrical equivalent circuit of the 3-pole (WE, RE and CE) circuit that constitutes the electrochemical cell; and the choice of an inductive or capacitive element is a matter of convenience and in no way does it suggest the inductive or capacitive behavior of the electrode $[22,23]$, and it can even have negative values [29]. 
Table 1. Fitting results for the real and pseudo reference electrodes with agar gelled and liquid electrolyte.

\begin{tabular}{lrrrcr}
\hline & & & \multicolumn{2}{c}{ CPE } & \\
\cline { 4 - 5 } & $L\left(\mu \mathrm{H} \cdot \mathrm{cm}^{2}\right)$ & $\operatorname{Re}\left(\Omega \cdot \mathrm{cm}^{2}\right)$ & \multicolumn{1}{c}{$\mathrm{Y}$} & $\alpha$ & Chi-Sqr \\
& & & $\left(\mu \mathrm{S} \mathrm{s}^{\alpha} \mathrm{cm}^{-2}\right)$ & $\alpha$ & \\
\hline AA-SRE & $-8.8 \pm 0.9$ & $418 \pm 2$ & $13.65 \pm 0.08$ & $0.828 \pm 0.001$ & $4.00 \mathrm{E}-03$ \\
AA-StdRE & $-3.8 \pm 0.3$ & $126 \pm 1$ & $14.05 \pm 0.08$ & $0.827 \pm 0.001$ & $2.81 \mathrm{E}-03$ \\
LIQ- SRE & $-49 \pm 6$ & $1384 \pm 6$ & $17.84 \pm 0.09$ & $0.805 \pm 0.002$ & $6.85 \mathrm{E}-03$ \\
LIQ- StdRE & $280 \pm 10$ & $750 \pm 2$ & $15.90 \pm 0.05$ & $0.792 \pm 0.001$ & $1.53 \mathrm{E}-03$ \\
\hline
\end{tabular}

Fit results are presented in table 1. Comparing experimental and calculated Re values, it can be observed that, for the pseudo RE, the experimental value with agar is much higher and about $10 \%$ lower for the liquid electrolyte. With the real $\mathrm{RE}$, the experimental value is about $10 \%$ lower for the agar, and half the value for the liquid. A higher experimental value can be attributed to the contribution of other elements (such as interfacial impedances between the electrolyte and the RE), but a lower experimental value has no physical explanation, thus it is clearly caused by an artifact in this high frequency region [23]. Considering that in corrosion measurements a $10 \%$ deviation from the theoretical value can be considered reasonable, we can derive two practical consequences. In very low conductivity electrolyte as the artificial rain, the use of the real RE causes the presence of an artifact that, at least, affects the region of the electrolyte response, while the pseudo RE gives a more reliable result. With the agar gelled electrolyte (with low but higher conductivity than the liquid), it may be possible to use a real RE with no overlapping of parasitic responses, while the use of a pseudo-RE adds additional resistance to the highfrequency part of the EIS spectrum. In any case, this contribution can be separated from the contributions of the other elements of the corrosion system, and the results obtained for the region of interest -corresponding to faradaic processes and passive layers or coatings- are the same with both pseudo and real reference electrodes.

\subsection{The influence of the WE-RE distance}

The distance and relative position between electrodes is another relevant parameter affecting the cell response [29,33], since it will influence the values of the capacitances and resistances between the electrodes in the 3-pole cell. To analyze the influence of this parameter in our cell and optimize the RE-WE distance, a series of measurements at different distances with both Std-RE and pseudo-RE electrodes were carried out. Figure 5 shows the EIS spectra with both RE at three different RE-WE distances: $2.0 \mathrm{~mm}, 3.2 \mathrm{~mm}$ and $4.4 \mathrm{~mm}$, which may give around 98,142 and $196 \Omega$ for the electrolyte resistance between them. Results from fitting the experimental data to the equivalent circuit are presented in table 2. 

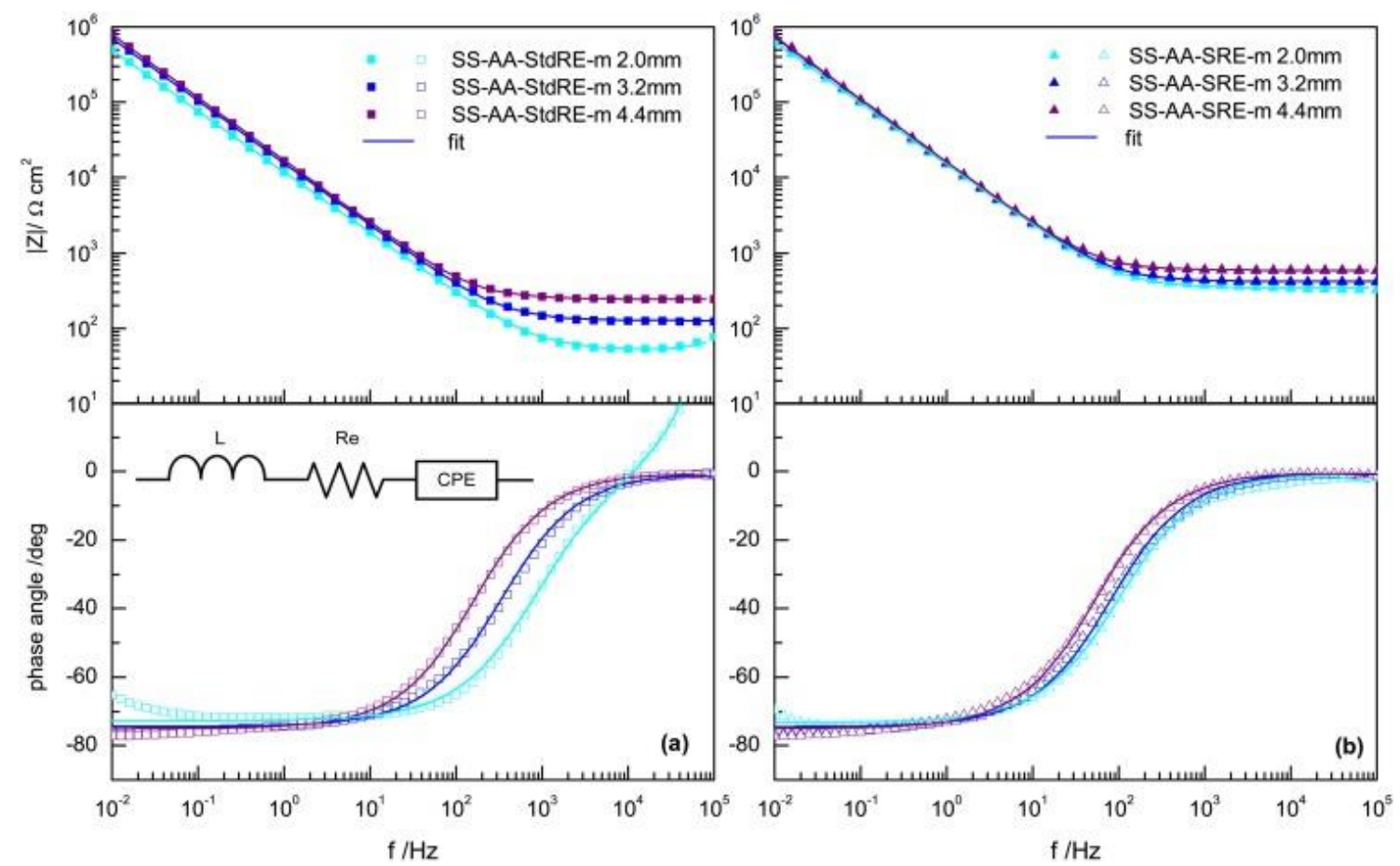

Fig. 5. Effect of the distance between the reference and the working electrode for a real reference electrode (a) and a pseudo reference electrode (b).

Table 2. Fitting results at different distances for the real and pseudo reference electrodes. $R_{\text {cal }}$ is the value estimated for Re from equation [1]

\begin{tabular}{|c|c|c|c|c|c|c|}
\hline & \multirow[b]{2}{*}{$\mathrm{L}\left(\mu \mathrm{H} \cdot \mathrm{cm}^{2}\right)$} & \multirow[b]{2}{*}{$\operatorname{Re}\left(\Omega \cdot \mathrm{cm}^{2}\right)$} & \multicolumn{2}{|c|}{ CPE } & \multirow{2}{*}{$\begin{array}{c}\mathrm{R}_{\mathrm{cal}} \\
\left(\Omega \cdot \mathrm{cm}^{2}\right)\end{array}$} & \multirow[b]{2}{*}{ Chi-Sqr } \\
\hline & & & $\begin{array}{c}Y \\
\left(\mu S s^{\alpha} \mathrm{cm}^{-2}\right)\end{array}$ & $\alpha$ & & \\
\hline AA StdRE $2.0 \mathrm{~mm}$ & $82 \pm 2$ & $52 \pm 1$ & $19.1 \pm 0.1$ & $0.808 \pm 0.001$ & 98 & $3.10 \mathrm{E}-03$ \\
\hline AA StdRE $3.2 \mathrm{~mm}$ & $-3.8 \pm 0.3$ & $124 \pm 1$ & $14.05 \pm 0.04$ & $0.827 \pm 0.001$ & 142 & $1.20 \mathrm{E}-03$ \\
\hline AA StdRE $4.4 \mathrm{~mm}$ & $-6 \pm 4$ & $243 \pm 1$ & $12.78 \pm 0.03$ & $0.834 \pm 0.001$ & 196 & $9.89 \mathrm{E}-04$ \\
\hline AA SRE $2.0 \mathrm{~mm}$ & $-33 \pm 9$ & $342 \pm 1$ & $14.99 \pm 0.06$ & $0.814 \pm 0.001$ & 98 & 2.60E-03 \\
\hline AA SRE $3.2 \mathrm{~mm}$ & $-1.8 \pm 0.9$ & $421 \pm 2$ & $13.65 \pm 0.08$ & $0.828 \pm 0.001$ & 142 & $3.35 \mathrm{E}-03$ \\
\hline AA SRE $4.4 \mathrm{~mm}$ & $21 \pm 2$ & $587 \pm 1$ & $13.50 \pm 0.1$ & $0.808 \pm 0.001$ & 196 & $2.50 \mathrm{E}-03$ \\
\hline
\end{tabular}

Pseudo-inductive responses are clearly present when using the real RE in the closest position $(2.0 \mathrm{~mm})$ while their value decreases as RE-WE distance increases. For $3.2 \mathrm{~mm}$ distance the spectra does not appear to be distorted but there is still a slight inductive contribution in the equivalent circuit. For the pseudo-RE pseudo-inductive effects are negligible (in fact, fitting the spectra without the pseudo-inductive element yield the same results for other elements in the circuit) although the electrode contributes to the uncompensated resistance.

The values of CPE are all very close and can be considered equal for all setup but the $2.0 \mathrm{~mm}$ with a standard RE suggesting that the RE parasitic contribution (either inductive or resistive) does not affect the results from the stainless steel WE. This means that as long as the uncompensated resistance (Re) can be separated from the WE response, both RE electrodes are valid. To minimize interferences of artifacts in the frequency ranges of interest for the corrosion 
studies, the lower distance is more convenient when a pseudo RE is used not to increase the Re value. On the contrary, when using a standard RE a higher distance allows avoiding inductive artifact. The CPE values obtained with the pseudo RE are a little less sensitive to the different WE-RE distances tested. It has to be considered that, especially in field measurements on irregular surfaces, the real WE-RE may be slightly different (lower) from the design distance, due to the pressure applied to adapt the gel to the WE surface.

\subsection{Bronze working electrode}

As artifacts are the result of interactions between the three electrodes $[22,23]$ the change in the nature of the WE may increase its effects or overlap with the region of interest when measuring other surfaces. For this reason, once the contribution/behavior or the cell is clear enough it is necessary to verify this is also valid for bronze, which is probably the most relevant material for this application.

Thus, EIS spectra with the real and pseudo RE have been acquired on laminated bronze coupons at the two selected distances, $3.2 \mathrm{~mm}$ and $4.4 \mathrm{~mm}$. Graphical and numerical results are presented in figure 6 and table 3 respectively. EIS spectra have been fitted to the equivalent circuit in figure 6 , where Re is the uncompensated resistance, CPE1 and R1 represent the double layer and the charge transfer resistance while $\mathrm{W}$ in associated to diffusion of copper ions within the oxide layer and the electrolyte. This equivalent circuit has been previously used to explain the behavior of copper and bronze in mild neutral electrolytes [18, 34]. Results from bronze coupons are coherent with those obtained for stainless steel, Re values are almost identical for the same setup, while the rest of parameters are reasonably similar for the different setups. Pseudoinductive artifacts are only appreciable for the lower RE-WE distance with the real reference, thus same considerations on RE and distances can be made for bronze.

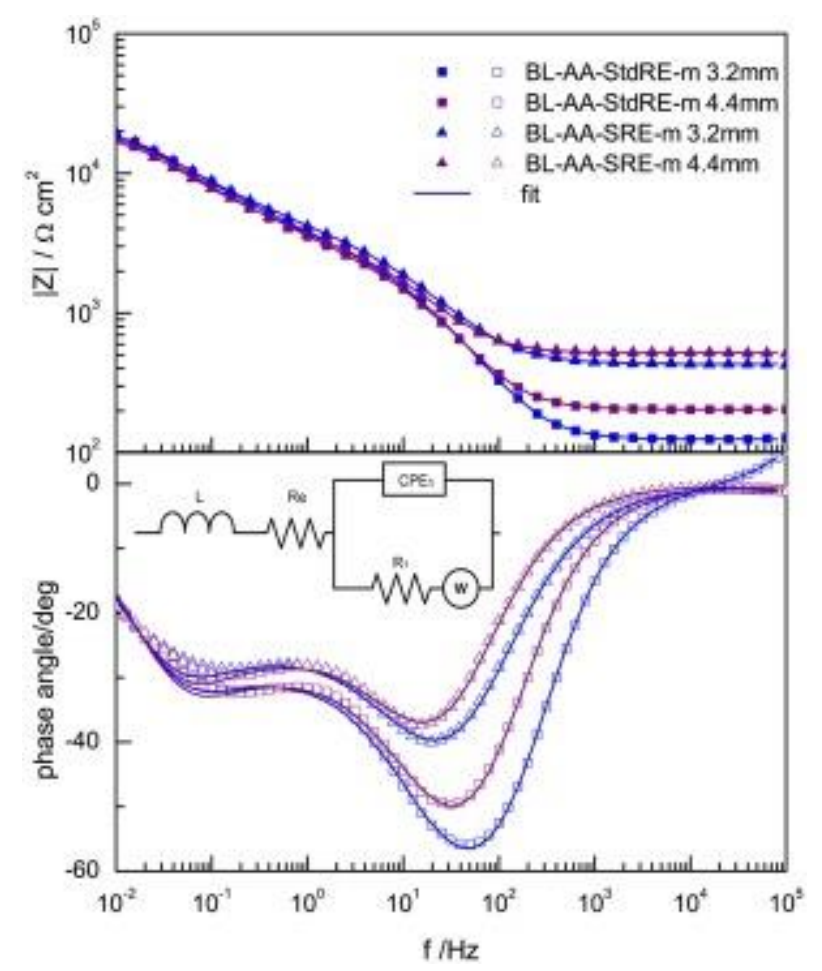

Fig. 6. EIS spectra comparing a real reference and a pseudo reference electrode at different distances on bronze coupons. 
Table 3. Fitting results at different distances for the real and pseudo reference electrodes on bronze coupons.

\begin{tabular}{|c|c|c|c|c|c|c|c|c|c|}
\hline & \multirow[b]{2}{*}{$\begin{array}{c}\mathrm{L} \\
\left(\mu \mathrm{H} \cdot \mathrm{cm}^{2}\right)\end{array}$} & \multirow[b]{2}{*}{$\begin{array}{c}\operatorname{Re} \\
\left(\Omega \cdot \mathrm{cm}^{2}\right)\end{array}$} & \multicolumn{2}{|c|}{ CPE1 } & \multirow[b]{2}{*}{$\begin{array}{c}\mathrm{R} 1 \\
\left(\Omega \cdot \mathrm{cm}^{2}\right)\end{array}$} & \multicolumn{3}{|c|}{ W } & \multirow[b]{2}{*}{$\begin{array}{l}\text { Chi- } \\
\text { Sqr }\end{array}$} \\
\hline & & & $\begin{array}{c}Y \\
\left(\mu \mathrm{S} \mathrm{s}^{\alpha} \mathrm{cm}^{-}\right. \\
\left.{ }^{2}\right)\end{array}$ & $\alpha$ & & $\begin{array}{c}\mathrm{Rw} \\
\left(\mathrm{k} \Omega \cdot \mathrm{cm}^{2}\right)\end{array}$ & $T_{w}(s)$ & $\alpha_{w}$ & \\
\hline BL StdRE & $1.95 \pm$ & $124.6 \pm$ & $95+02$ & $0.915 \pm$ & $1430+50$ & $20.7 \pm$ & $22.0 \pm$ & $0.396 \pm$ & $4.42 \mathrm{E}$ \\
\hline $3.2 \mathrm{~mm}$ & 0.06 & 0.3 & $9.5 \pm 0.2$ & 0.003 & $1430 \pm 50$ & 0.2 & 0.7 & 0.003 & -04 \\
\hline $\begin{array}{l}\text { BL StdRE } \\
4.4 \mathrm{~mm}\end{array}$ & $-4 \pm 3$ & $\begin{array}{r}203.9 \pm \\
0.5\end{array}$ & $10.7 \pm 0.4$ & $\begin{array}{r}0.911 \pm \\
0.005\end{array}$ & $1390 \pm 60$ & $\begin{array}{r}19.2 \pm \\
0.2\end{array}$ & $\begin{array}{r}19.8 \pm \\
0.7\end{array}$ & $\begin{array}{r}0.409 \pm \\
0.003\end{array}$ & $\begin{array}{r}7.01 \mathrm{E} \\
-04\end{array}$ \\
\hline BL SRE $3.2 \mathrm{~mm}$ & $-15 \pm 7$ & $431 \pm 1$ & $13.2 \pm 0.6$ & $\begin{array}{r}0.834 \pm \\
0.007\end{array}$ & $\begin{array}{r}2000 \pm \\
100\end{array}$ & $\begin{array}{r}20.3 \pm \\
0.4\end{array}$ & $24 \pm 1$ & $\begin{array}{r}0.394 \pm \\
0.005\end{array}$ & $\begin{array}{r}8.64 \mathrm{E} \\
-04\end{array}$ \\
\hline BL SRE $4.4 \mathrm{~mm}$ & $-18 \pm 9$ & $517 \pm 2$ & $12.9 \pm 0.7$ & $\begin{array}{r}0.885 \pm \\
0.009\end{array}$ & $1510 \pm 90$ & $\begin{array}{r}18.1 \pm \\
0.3\end{array}$ & $22 \pm 1$ & $\begin{array}{r}0.406 \pm \\
0.005\end{array}$ & $\begin{array}{r}1.25 \mathrm{E} \\
-03\end{array}$ \\
\hline
\end{tabular}

\subsection{In situ measurements}

The final step is to test if the cell allows obtaining good quality data out of the ideal situation of model samples and laboratory conditions. So, along with the development of the cell design, it has been assayed in different materials and case studies [35, 36]. These examples have allowed to validate the cell performance and to improve the design according to different difficulties being observed. In this section an example of EIS spectra recorded on a twentieth century stainless steel sculpture with the G-PE cell (stainless steel pseudo RE) is compared to laboratory measurements (figure $\mathrm{x}$ ). The sculpture is Mediterránea III, made by the Spanish sculptor Martín Chirino in 1971, which is owned by the Museo Nacional Centro de Arte Reina Sofía and exposed at the Museo de Escultura de Leganés. Although the spectra of the sculpture shows a couple of small discontinuities in the phase angle, it can be considered a good quality field measurement, showing an identical profile to those obtained on coupons under laboratory conditions. Slight differences at intermediate and high frequencies -higher impedance for the sculpture- can be attributed to the ageing of the passive layer of the metal exposed outdoors.

As an example of a bronze outdoor sculpture measurements on a bronze sphinx at the main façade of the Spanish National Archaeological Museum (MAN) in Madrid are compared with a cast bronze coupon (figure). The two bronze sphinxes from the MAN façade were restored a few years ago and protected with an acrylic coating (Incralac), commonly used for conservation treatments of copper-alloy sculptures [16]. The EIS spectra of the right sphinx two years after the treatment is compared to a bronze coupon with a dark sulfide patina prepared in the traditional way that has been also coated with Incralac and exposed to the atmosphere in Madrid for the same period. Again, results obtained in field measurements are comparable to laboratory results, considering the differences in the materials, validating the performance of the G-PE cell for in situ conservation assessment. 

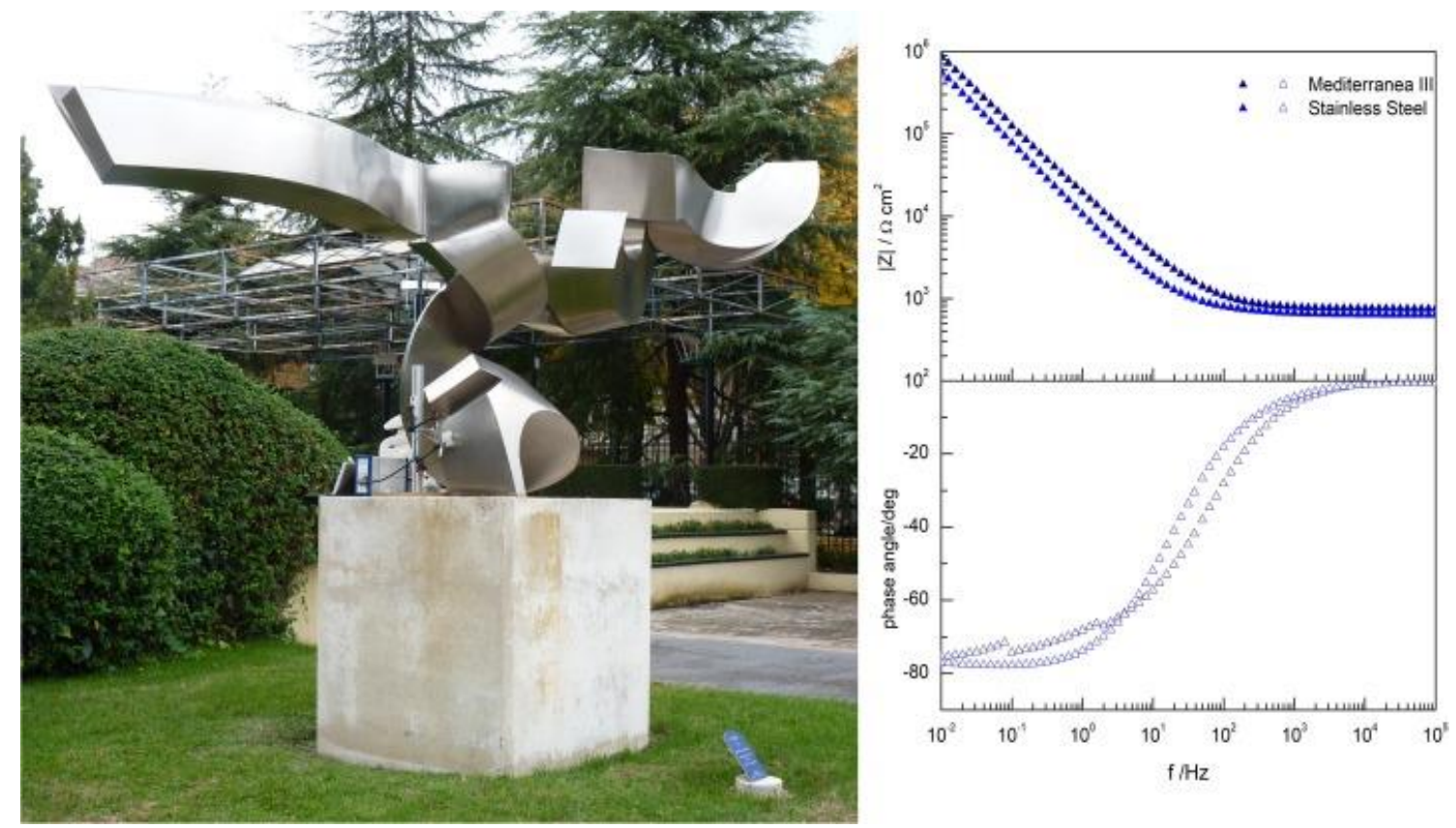

Fig. 7. Comparison between laboratory measures on stainless steel coupons and field measurements on the stainless steel sculpture, Mediterránea III, by Martín Chirino.
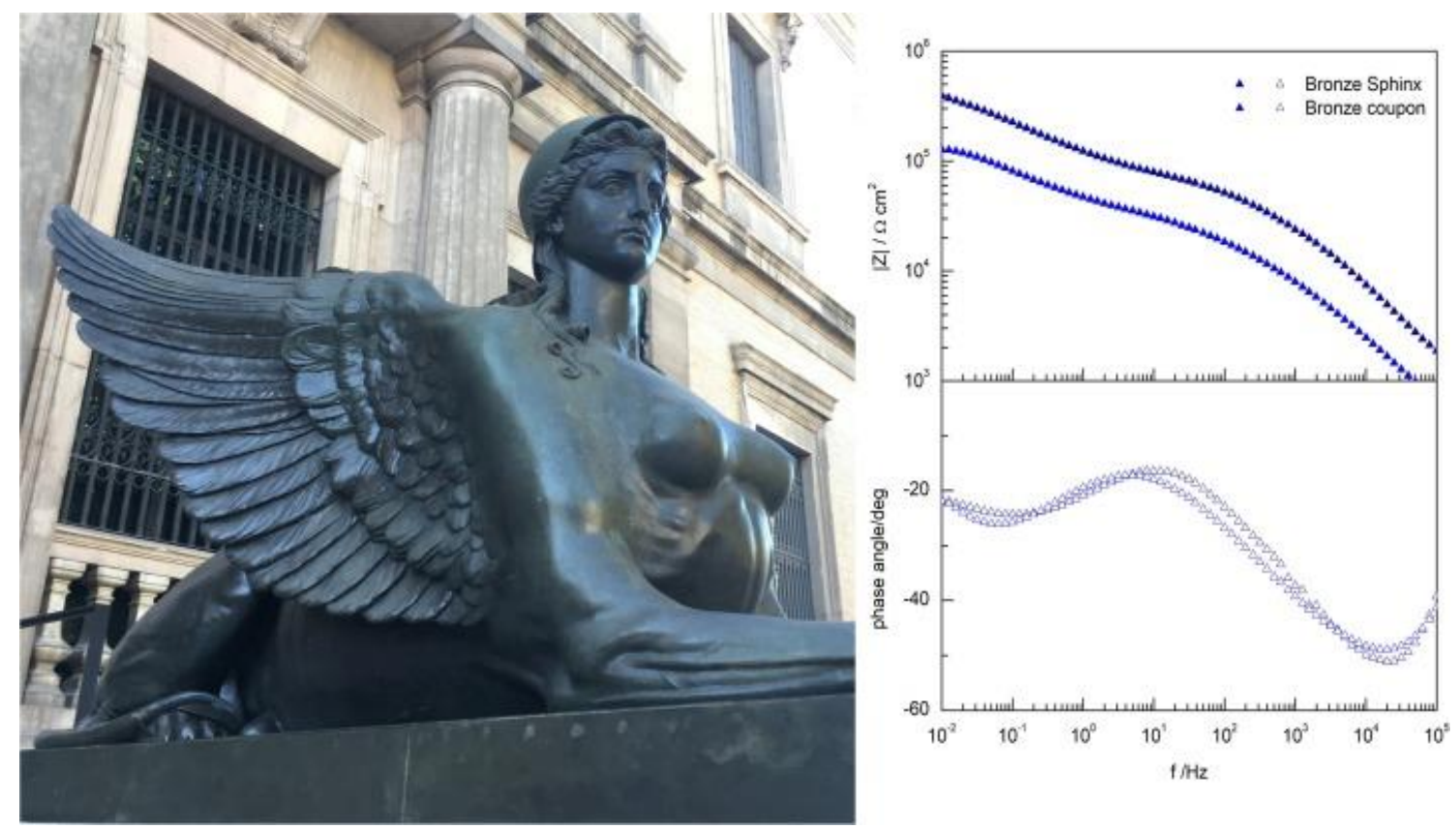

Fig. 8. Comparison between EIS spectra on an aged cast bronze coupon with a sulfide patina and Incralac coating with field measurements on right bronze sphinx from the Museo Arqueológico Nacional, restored and protected with Incralac.

\section{Conclusions}

Results support the suitability of the G-PE cell as an electrochemical sensor for corrosion measurements on metallic cultural heritage. 
The analysis of different design parameters has allowed to improve the cell and to understand the influence of the nature and geometry of the electrodes in the EIS response. This has allowed also separating possible parasitic contributions from the response of the working electrode. As it has been demonstrated, the cell can be used either with a real reference electrode or with a pseudo-reference electrode, as a matter of convenience. When using a real reference electrode attention has to be paid not to place it too close to the working electrode surface to avoid pseudo-inductive effects. When using a pseudo-reference electrode it is more convenient using a closer distance to reduce the uncompensated resistance.

The G-PE cell has demonstrated to be a versatile and useful tool for conservation assessment, giving good results both in laboratory samples and field measurements.

\section{Acknowledgements}

This work was supported by the Spanish Ministry of Economy and Competitiveness (projects HAR2011-22402 and HAR2014-54893-R, and grant BES-2012-052716); by the CNR-STM grant "In situ electrochemical techniques for metal artworks conservation" and the Comunidad de Madrid (project GEOMATERIALES2 S2013/MIT-2914). Authors want to thank Rosa Ma Izquierdo and Israel, from the Museo de Escultura de Leganés, Teresa Espinosa from the Museo Arqueológico Nacional, Codina Escultura, and Francisco García from the CENIM.

\section{References}

[1] V. Otieno-Alego, D. Hallam, A. Viduka, G. Heath, D. Creagh, Electrochemical impedance studies of the corrosion resistance of wax coatings on artificially patinated bronze, in: J. Ashton, D. Hallam (Eds.), Metal 98 International Conference on Metal Conservation James \& James, Draguignan-Figanières (France), 1998, pp. 315-9

[2] G. Bierwagen, T.J. Shedlosky, L.A. Ellingson, Electrochemical studies of the protection of bronzes from corrosion by organic coatings, in: I. MacLeod, J.M. Theile, C. Degrigny (Eds.), Metal 01 International Conference on Metal Conservation Western Australian Museum, Santiago (Chile), 2001, pp. 291-6.

[3] G. Bierwagen, T.J. Shedlosky, K. Stanek, Developing and testing a new generation of protective coatings for outdoor bronze sculpture, Progress in Organic Coatings, 48(2003) 28996.

[4] L.A.B. Ellingson, L.B.; Shedlosky, T. J.; Bierwagen, G. P.; De la Rie, E. René, The use of electrochemical impedance spectroscopy in the evaluation of coatings for outdoor bronze, Studies in Conservation, 49(2004) 53-62.

[5] E. Joseph, P. Letardi, R. Mazzeo, S. Prati, M. Vandini, Innovative treatments for the protection of outdoor bronze monuments, in: C. Degrigny, R. Van Lang, I. Joosten, B. Ankersmith (Eds.), Metal 07 Interim meeting of the ICOM-CC Metal WG, Rijksmuseum Amsterdam, Amsterdam (The Neatherlands), 2007, pp. 71-7.

[6] E. Cano, D.M. Bastidas, V. Argyropoulos, S. Fajardo, A. Siatou, J.M. Bastidas, et al., Electrochemical characterization of organic coatings for protection of historic steel artefacts, Journal of Solid State Electrochemistry, 14(2010) 453-63.

[7] N. Swartz, T.L. Clare, On the protective nature of wax coatings for culturally significant outdoor metalworks: Microstructural flaws, oxidative changes, and barrier properties, Journal of the American Institute for Conservation, 54(2015) 181-201. 
[8] P. Letardi, Electrochemical impedance measurements in the conservation of metals, in: D.C. Creagh, O.A. Bradley (Eds.), Radiation in Art and Archeometry, Elsevier Science B.V, Amsterdam, 2000, pp. 15-39.

[9] P. Letardi, R. Spiniello, Characterisation of bronze corrosion and protection by contact-probe electrochemical impedance measurements, in: I. MacLeod, J.M. Theile, C. Degrigny (Eds.), Metal 01 International Conference on Metal Conservation Western Australian Museum, Santiago (Chile), 2001, pp. 316-9.

[10] E. Angelini, S. Grassini, S. Corbellini, G.M. Ingo, T. De Caro, P. Plescia, et al., Potentialities of XRF and EIS portable instruments for the characterisation of ancient artefacts, Applied Physics A: Materials Science and Processing, 83(2006) 643-9.

[11] E. Angelini, S. Grassini, M. Parvis, F. Zucchi, An in situ investigation of the corrosion behaviour of a weathering steel work of art, Surface and Interface Analysis, 44(2012) 942-6.

[12] T.L. Clare, A. England, N. Swartz, K. Hosbein, Onsite electrochemical monitoring method for early detection of coating failure, in: V.G. Ewan Hyslop, Lore Troalen, Lyn Wilson (Ed.) METAL 2013, Edinburg, 2013.

[13] S. Li, Y.G. Kim, S. Jung, H.S. Song, S.M. Lee, Application of steel thin film electrical resistance sensor for in situ corrosion monitoring, Sensors and Actuators, B: Chemical, 120(2007) 368-77.

[14] S. Muralidharan, T.H. Ha, J.H. Bae, Y.C. Ha, H.G. Lee, K.W. Park, et al., Electrochemical studies on the performance characteristics of solid metal-metal oxide reference sensor for concrete environments, Sensors and Actuators, B: Chemical, 113(2006) 187-93.

[15] P.G. Venancio, R.A. Cottis, R. Narayanaswamy, J.C.S. Fernandes, Optical sensors for corrosion detection in airframes, Sensors and Actuators, B: Chemical, 182(2013) 774-81.

[16] B. Ramírez Barat, A. Crespo, E. García, S. Díaz, E. Cano, An EIS study of the conservation treatment of the bronze sphinxes at the Museo Arqueológico Nacional (Madrid), Journal of Cultural Heritage, 24(2017) 93-9.

[17] E. Cano, D. Lafuente, D.M. Bastidas, Use of EIS for the evaluation of the protective properties of coatings for metallic cultural heritage: A review, Journal of Solid State Electrochemistry, 14(2010) 381-91.

[18] B. Ramírez Barat, E. Cano, The use of agar gelled electrolyte for in situ electrochemical measurements on metallic cultural heritage, Electrochimica Acta, 182(2015) 751-62.

[19] P. Letardi, Electrochemical measurements in the conservation of metallic heritage artefacts: An overview, Corrosion and Conservation of Cultural Heritage Metallic Artefacts2013, pp. 12648.

[20] E. Cano, A. Crespo, D. Lafuente, B. Ramírez Barat, A novel gel polymer electrolyte cell for insitu application of corrosion electrochemical techniques, Electrochemistry Communications, 41(2014) 16-9.

[21] P. Letardi, B. Ramirez Barat, E. Cano, Analysis of the influence of the electrochemical cell setup for corrosion measurements on metallic cultural heritage, European Corrosion Congress, EUROCORR 2017, Prague, Czech Republic, 2017.

[22] S. Fletcher, The two-terminal equivalent network of a three-terminal electrochemical cell, Electrochemistry Communications, 3(2001) 692-6.

[23] A. Sadkowski, J.P. Diard, On the Fletcher's two-terminal equivalent network of a threeterminal electrochemical cell, Electrochimica Acta, 55(2010) 1907-11.

[24] G. Hsieh, S.J. Ford, T.O. Mason, L.R. Pederson, Experimental limitations in impedance spectroscopy: Part I - simulation of reference electrode artifacts in three-point measurements, Solid State lonics, 91(1996) 191-201.

[25] G. Hsieh, T.O. Mason, E.J. Garboczi, L.R. Pederson, Experimental limitations in impedance spectroscopy: Part III. Effect of reference electrode geometry/position, Solid State Ionics, 96(1997) 153-72.

[26] G. Hsieh, T.O. Mason, L.R. Pederson, Experimental limitations in impedance spectroscopy: Part II - electrode artifacts in three-point measurements on Pt/YSZ, Solid State lonics, 91(1996) 203-12. 
[27] P. Vanýsek, H. Tavassol, K.L. Pilson, Electrochemistry in the electrochemical cells: There is more than just the working electrode, ECS Transactions, 1 ed.2014, pp. 145-55.

[28] S.N. Inamdar, M.A. Bhat, S.K. Haram, Construction of Ag/AgCl Reference Electrode from Used Felt-Tipped Pen Barrel for Undergraduate Laboratory, Journal of Chemical Education, 86(2009) 355-6.

[29] M. Balabajew, B. Roling, Minimizing Artifacts in Three-electrode Double Layer Capacitance Measurements Caused by Stray Capacitances, Electrochimica Acta, 176(2015) 907-18.

[30] E. Bernardi, C. Chiavari, C. Martini, L. Morselli, The atmospheric corrosion of quaternary bronzes: An evaluation of the dissolution rate of the alloying elements, Applied Physics A: Materials Science and Processing, 92(2008) 83-9.

[31] H. Göhr, M. Mirnik, C.A. Schiller, Distortions of high frequency electrode impedance. Their causes and how to avoid them, Journal of Electroanalytical Chemistry, 180(1984) 273-85.

[32] F. Mansfeld, S. Lin, Y.C. Chen, H. Shih, Minimization of High-Frequency Phase Shifts in Impedance Measurements, Journal of the Electrochemical Society, 135(1988) 906-7.

[33] S. Chechirlian, P. Eichner, M. Keddam, H. Takenouti, H. Mazille, A specific aspect of impedance measurements in low conductivity media. Artefacts and their interpretations, Electrochimica Acta, 35(1990) 1125-31.

[34] Y. Feng, W.K. Teo, K.S. Siow, K.I. Tan, A.K. Hsieh, The corrosion behaviour of copper in neutral tap water. Part I: Corrosion mechanisms, Corrosion Science, 38(1996) 369-85.

[35] A. Crespo, B. Ramírez Barat, D. Lafuente, S. Diaz, E. García, E. Cano, Non-destructive electrochemical evaluation of the patinas on the bronze sphinxes of the Museo Arqueológico Nacional in Madrid, Art' 1411 th International Conference on non-destructive investigations and microanalysis for the diagnostics and conservation of cultural and environmental heritage, Madrid, 2014.

[36] B. Ramírez Barat, E. Cano, Evaluación in situ de recubrimientos protectores para patrimonio cultural metálico mediante espectroscopía de impedancia electroquímica, Ge-conservación, 8(2015) 6-13. 